\title{
El compromiso de Gilead en la lucha contra el COVID-19: Cuando innovación y solidaridad convergen para dar una respuesta sanitaria global
}

\author{
Gilead \\ DOI: https://doi.org/10.37536/RIECS.2021.6.1.269 \\ Recibido: 10/05/2021; Aceptado: 27/05/2021; Publicado: 31/05/2021
}

La aparición y expansión del SARS-CoV-2, cuyos primeros casos de personas infectadas en España se detectaron a finales de enero de 2020, puso en jaque a la población mundial, sin saber por entonces que cambiaría la vida como se conocía hasta entonces. Antes de que la situación se convirtiera en una emergencia global, Gilead, compañía biofarmacéutica con más de 30 años de experiencia en el campo de la virología y otras enfermedades graves, ya daba pasos firmes en la búsqueda de soluciones, poniendo al servicio de las autoridades sanitarias tanto nacionales como internacionales todo su conocimiento y experiencia en virología.

Ante una crisis mundial sin precedentes que ha causado estragos en todas las facetas de la sociedad y que acumula millones de personas infectadas y fallecidas, Gilead dio un paso al frente y se convirtió en una de las primeras compañías en actuar y liderar la lucha contra esta pandemia. Remdesivir, su molécula desarrollada diez años atrás y que había mostrado actividad contra patógenos virales como el Ébola, fue desarrollado y aprobado en tan solo 6 meses convirtiéndose en el primer tratamiento de la enfermedad por COVID-19. Remdesivir ${ }^{1}$ está indicado para el tratamiento de la enfermedad por coronavirus 2019 (COVID-19) en adultos y adolescentes (de 12 años de edad y mayores con un peso corporal de al menos $40 \mathrm{~kg}$ ) con neumonía que requieren oxígeno suplementario. Su rápido desarrollo desafió lo conocido hasta ahora en materia de tiempos de I+D de nuevos tratamientos que se estima en una media de diez años. En julio del 2020, remdesivir fue incluido por la Agencia Española del Medicamento como un medicamento esencial en la gestión sanitaria de la pandemia.

El compromiso adquirido por Gilead para encontrar una respuesta a una crisis como esta le permitió aportar soluciones eficaces y desarrollar iniciativas responsables en un doble ámbito. Por un lado, en el plano científico con el desarrollo de su antiviral que, en la actualidad, es empleado en más de 50 países al proporcionar beneficios clínicos a los pacientes hospitalizados con COVID-19, evitando que la enfermedad avance, reduciendo las tasas de mortalidad y acelerando la recuperación con la consecuente liberación de los limitados recursos sanitarios, colapsados durante mucho tiempo². Y, por otro, en el social, colaborando activamente para aportar soluciones a distintos organismos y colectivos para que pudieran hacer frente a esta complicada situación.

\footnotetext{
${ }^{1}$ https://cima.aemps.es/cima/dochtml/ft/1201459001/FT_1201459001.html

2 https://www.nejm.org/doi/full/10.1056/nejmoa2007764

RIECS 2021, 6, 1; ISSN: 2530-2787
} 


\section{Una investigación contrarreloj sin precedentes}

Ante un escenario de alta complejidad, Gilead realizó en pocos meses lo que, en una situación normal, conlleva años con el objetivo de poder contribuir a dar una respuesta ágil y eficaz a la situación generada por la COVID-19. La autorización de remdesivir en un amplio número de países y regiones, entre ellos la Unión Europea y Estados Unidos, permitió que el antiviral estuviera al alcance de todos aquellos pacientes que lo necesitaron. Tan solo en España, más de 15.000 pacientes recibieron este tratamiento sin coste alguno para el Sistema Nacional de Salud. Igualmente, y para contribuir a frenar el impacto de la pandemia a la par que lideraba la investigación, Gilead donó toda la producción del fármaco existente hasta junio de 2020 -1,5 millones de viales- para hacer posible un acceso rápido y permitir la realización de ensayos clínicos; así como programas de uso compasivo y de acceso expandido a nivel mundial.

La excelencia de sus investigadores y de su sistema sanitario hicieron que rápidamente España tuviera un papel clave en el programa de desarrollo acelerado de esta innovación. El compromiso de la compañía con nuestro país le ha valido para ser el segundo en el mundo con más hospitales involucrados en el estudio y análisis del antiviral con 37 centros participantes en los ensayos clínicos y programas de acceso temprano al fármaco.

En la actualidad, Gilead mantiene en marcha el programa de desarrollo de su innovación, estudiando su combinación con otros medicamentos; en otros grupos poblaciones, como los pacientes pediátricos o mujeres embarazadas; o nuevas fórmulas, como la inhalada, que simplifiquen su administración en entornos ambulatorios.

A pesar de tratarse de un proceso de fabricación complejo y laborioso, ya que algunos procesos químicos tardan varias semanas y su elaboración requiere de condiciones especiales, Gilead reforzó su capacidad de producción, multiplicándola por 50, para llegar a ofrecer varios millones de viales más a lo largo de este 2021 en caso necesario. Para lograrlo, realizó un gran esfuerzo para mejorar sus procesos y acortar el plazo de fabricación de remdesivir de 12 a 6 meses, además de ampliar su red global de producción. A nivel interno, la compañía reorganizó en 2020 algunas de sus plantas para reorientarlas a la producción urgente de esta opción terapéutica. A nivel externo, creó una red de socios diversificados geográficamente para unir esfuerzos y producir más de lo que cualquier compañía individualmente podría conseguir. Así, desde el comienzo Gilead ha conseguido hacer llegar su innovación a quien la necesite y cumpliese los criterios necesarios para su administración.

\section{Gilead: solidaridad sin límites más allá de la investigación}

El compromiso investigador de la compañía se vio reforzado por un esfuerzo solidario nunca visto antes. Sólo en España, Gilead destinó más de 1,6 millones de euros para implementar medidas socio-sanitarias. Para ello, trabajó con los servicios de salud de las doce Comunidades Autónomas más afectadas por la COVID-19 facilitándoles el material que necesitaban. Y, durante la fase más aguda de la pandemia, colaboró estrechamente con la SEFH (Sociedad Española de Farmacia Hospitalaria) para mejorar la seguridad de los pacientes y farmacéuticos hospitalarios durante la crisis sanitaria. Un acuerdo que permitió que 111 centros se unieran a esta iniciativa y casi 3.400 profesionales de la farmacia hospitalaria vieran mejoradas sus medidas de seguridad. Igualmente, la compañía donó más de 50 equipos informáticos para los controles de enfermería del hospital de campaña de IFEMA, 150.000 mascarillas auto filtrantes FFP2 y más de 40.000 test diagnósticos PCR.

Sin embargo, estas ayudas no se limitaron solo al colectivo sanitario. A través de un acuerdo con Cruz Roja se prestó soporte para la adquisición de material en albergues y hospitales de campaña. Además de habilitar una convocatoria extraordinaria, en colaboración con CESIDA, a la que se acogieron más de 30 ONGs para ayudar a las poblaciones más vulnerables y personas en riesgo de exclusión en la adquisición de material de protección, facilitar el transporte de medicinas para pacientes que lo necesiten o la compra de alimentos y productos de primera necesidad.

Asimismo, desde una perspectiva internacional, la compañía habilitó un fondo global, Gilead Cares, con más de 20 millones de dólares para ayudar a aquellos colectivos de pacientes y ONG's más afectados por esta crisis. 
Finalmente, ante la crisis vivida por el repunte de casos en la India, Gilead ha donado 450.000 viales de tratamiento para ayudar ante la emergencia. Además, la compañía está proporcionando a sus socios de licencia voluntaria asistencia técnica y apoyo para la incorporación de nuevas instalaciones a nivel local para la fabricación del principio activo de forma rápida.

Después de más de un año desde el estadillo estallido de la pandemia parece que ahora España comienza a ver el final, pero es el momento de un último esfuerzo. La investigación junto con el esfuerzo realizado por el sector sanitario y otros sectores fundamentales han señalado el camino. Por ello, ahora más que nunca Gilead sigue trabajando con la entrega y el compromiso del primer día, con un solo objetivo que hace menos de un año parecía imposible: acabar con el COVID-19. 